\title{
Proposal for a new oral disposition index with OGIS as a marker of insulin action
}

\begin{abstract}
Aim: The euglycemic clamp is the gold standard for measuring insulin action, but has a disadvantage that makes it impractical. There surrogates as OGIS, based on a mathematical model derived from kinetic studies of plasma glucose humane methods. It has better performance over other options (Matsuda, HOMA, Quicki). Searching an integrated manner the compensation capacity of the beta cell to different states of insulin sensitivity, disposition index, which serves as a predictor developed of incident diabetes. Can be calculated using surrogates indexes both secretion and action insulin. Present study proposes using OGIS as a marker of insulin action and a new disposition index.
\end{abstract}

Materials and methods: All OGTT of 3 to 5hours made in 2007 to 2013 at INNSZ were included. The secretion index and action of insulin were calculated too. The oral disposition index (IDO) was estimated as the product of (Delta 0-30insulin/delta 0-30glucose x (1/basal insulin). OGIS was used as a marker of insulin action and HOMA-B as a secretion marker. Their correlation and concordance were evaluated.

Results: Data from 2097 patients were collected, only 1619 with complete information were included in the analysis. Its main features were: $73 \%(1177)$ women and $27 \%(442) \mathrm{men}$; $816(50 \%)$ BMI $>30,500(31 \%)$ were overweight; $1039(64 \%)$ were categorized as normal glucose tolerance, 175(11\%) with IFG, 194(12\%) with IGT, 139(9\%) with IGT+IFG and finally $72(4 \%)$ with DM2. There were significant differences in the value of IDO by comparing status of glucose tolerance (normal:0.21, IFG:0.11, IGT:0.10, DM2:0.08, p<0.001) When OGIS was including showed increasing the magnitude of the difference between status of glucose tolerance (normal: 777, IFG: 438, IGT: 382, DM2: 349, p<0.001). The opposite phenomenon occurred when using HOMA-B as an indicator of beta cell function. The correlation between IDO and the new index based on OGIS was $0.773(\mathrm{p}<0.001)$. Considering as abnormal condition to the lowest quartile of both indicators showed agreement was moderate (kappa 0.518).

Conclusion: We showed an alternative index of disposition based on OGIS as surrogate insulin action. Has the advantage of a greater discrimination capability status of tolerance glucose compared to the original method.

Keywords: euglycemic clamp, oral glucose tolerance test, insulin action, OD
Volume 5 Issue 5 - 2017

Aguirre Karina, Mehta Roopa, Gulías Alfonso, Aguilar Carlos

Department of Endocrinology and Metabolism, Instituto

Nacional de Nutrición Salvador Zubirán, Mexico

Correspondence: Aguirre Karina, Department of Endocrinology and Metabolism, Instituto Nacional de Nutrición Salvador Zubirán, Mexico, Email kaguirre 198 I@gmail.com

Received: September 06, 2016 | Published: October 27, 2017
Abbreviations: IVGTT, intravenous glucose tolerance; OGTT, oral glucose tolerance test; ISI, insulinsensitivity index; IGT, impaired glucose tolerance; EII, early insulinogenic index; OGIS, oral glucose insulin sensitivity.

\section{Introduction}

The deficiencies in the secretion of $\beta$-cell and insulin resistance are the two major pathophysiological mechanisms of diabetes. Both can be demonstrated in individuals at high risk of developing long before hyperglycemia. ${ }^{1}$ Evaluation of insulin secretion in humans under physiological conditions has been a challenge due to the complex interplay between insulin action and hepatic extraction of it. ${ }^{2}$

The euglycemic clamp is the validated technique for measuring the action of insulin in vivo. It provides information about the amount of glucose metabolized by peripheral tissues during insulin stimulation. The clamp methodology has been developed and widely used by De Fronzo since $1979 .{ }^{3}$ Is considered the gold standard to measure the action of insulin, however, has some disadvantages which do not allow applying to large populations.

In the last two decades, several research groups have proposed alternative methods that attempt to evaluate simultaneously both the function of beta cell as the action of insulin on the basis of protocols both intravenous and oral.

The insulin secretion pattern allowing evaluation of the beta cells after a bolus intravenous injection of glucose, for example, during a test of intravenous glucose tolerance (IVGTT) or after ingestion glucose, for example, an oral glucose tolerance test (OGTT) or a mixed meal.

Oral tests are certainly more physiological that intravenous because incretin effect in OGTT and food because of the presence of nutrients, ie: proteins and fats.

Minimal model allows evaluating an index of insulin sensitivity by means of the intravenous glucose tolerance test. When the value of AIR is multiplied by disposal rate the result is called DISPOSITION INDEX and determines whether insulin secretion is appropriate to the level of action of the same.

The DISPOSITION INDEX shows the failure of the beta cell to compensate for insulin resistance in subjects at high risk for developing type 2 diabetes and impaired fasting glucose.

Prospective studies have shown that DISPOSICION INDEX is greatly reduced before the presence of hyperglycemia. Therefore, a 
low rate of DISPOSITION INDEX is an early marker of inadequate compensation of beta cells. ${ }^{4}$.

Using the minimal model intravenous, an oral minimal model was developed based on the oral glucose tolerance test (OGTT). It is less accurate but simpler to implement and it's often used in epidemiological or intervention studies. Also it assesses different aspects of beta cell function.

Some surrogate measures of insulin secretion and insulin sensitivity have been developed from the OGTT as are the HOMA (homeostasis model assessment). ${ }^{5}$ both HOMA B and HOMA IR index; QUICKI (quantitative insulin sensitivity check index). ${ }^{5}$ and Matsuda insulin sensitivity index (ISI). ${ }^{6-11}$

In 2001, OGIS was proposed as an index of insulin action derived of OGTT, based on a physiological model of glucose and insulin. This index is comparable to the calculation of glucose clearance obtained in the clamp. It was validated in thin and obese subjects with impaired fasting glucose and type 2diabetes.

This method use the values obtained from OGTT, was compared to the clamp being able to obtain a good correlation $(r=0.77, p=0.0001)$. Moreover this method has been tested independently showing that the performance of the other methods (Matsuda, HOMA, Quicki) is lower. ${ }^{7,12}$

Utzschneider et al. ${ }^{9}$ showed on the basis of the hyperbolic relationship of the components of the following formula between (delta 0-30 insulin/delta glucose $0-30 \times 1$ /fasting insulin), that their product known as ORAL disposition index $=$ ODI, is an actual measurement of the beta cell function and decreases progressively from individuals with oral normal glucose tolerance, glucose intolerance and diabetes $(p<0.001$ for all comparisons). Similar results were obtained when calculated using HOMA-S in place of 1 /fasting insulin. ${ }^{9}$

Indeed, the ODI has emerged as a valuable tool in clinical research by providing an integrated system of measuring the offset of the beta cell, while insulin secretion is appropriately evaluated against sensitivity to predominant insulin. A lower ODI is clearly present in subjects with pre-diabetes. THE ODI has approx. $70 \%$ heritability and can be a useful feature to identify genetic predisposition to DM. Increased ODI was associated with a lower risk of DM at 10years. OR $0.40 .95 \%$ CI 0.25- 0.66, $\mathrm{p}<0.001$ ) after adjusting for age, sex, BMI, fasting glucose and glucose $2 \mathrm{~h} .{ }^{9}$

This study proposed a new index of oral disposition on the basis of the values obtained from the OGTT using OGIS as an index of insulin action because of its demonstrated better correlation with clam versus other surrogate indices.

\section{Methodology}

A retrospective cross-sectional observational comparative study. Values of glucose and insulin curves for three to five hours made in the past five years at National Institute of Medical Sciences and Nutrition Salvador Zubirán were collected.

Review of relevant records was conducted to filial anthropometric data, age, sex, lipid profile, and drug history. The cases were selected based on inclusion criteria (patients over 18 years and both genders) and exclusion (previous diagnosis of T2DM, current pregnancy or lactation, treatment with metformin for any reason and incomplete anthropometric data on file).
Databases were provided by Aguilar, Carlos MD, Mehta, Roopa MD and Gulías, Alfonso MD. Also values of insulin and glucose curves for 3 and 5hours performed in 2013 were included.

We considered only one curve of glucose and insulin for each patient. Both basal values of glucose - insulin and values after $75 \mathrm{~g}$ glucose load at 30, 60, 90, 120, 180, 240 and 300min was taken. With which we cataloged each case according to the criteria of the ADA for its status of glucose tolerance (normal: fasting blood glucose $<100 \mathrm{mg} /$ $\mathrm{dl}$ and 2hours glucose $<140 \mathrm{mg} / \mathrm{dl}$; Impaired Glucose Fasting (IGF): fasting glucose 100 to $125 \mathrm{mg} / \mathrm{dl}$; Impaired glucose tolerance (IGT): 2hours glucose above $140 \mathrm{mg} / \mathrm{dl}$; IGF+IGT: fasting glucose above $100 \mathrm{mg} / \mathrm{dl}$ glucose and/or 2-hour glucose between 140 and 199 $\mathrm{mg} / \mathrm{dl}$; DM clinic: fasting blood glucose $\geq 126 \mathrm{mg} / \mathrm{dl}$ and/or 2 hours glucose $\geq 200 \mathrm{mg} / \mathrm{dl}$ ). We also calculated indices that evaluate insulin secretion. Early insulinogenic index (EII) (2): Delta0-30 insulin/delta 0-30glucose min; HOMA B: 20x insulin $(\mathrm{mUI} / \mathrm{ml}) / \mathrm{glucose}(\mathrm{mg} / \mathrm{dl})-$ 3.5 .

Indices that evaluate the action of insulin:

i. HOMA IR: Basal Insulin (mUI/ml) x fasting glucose (mg/dl)/405;

ii. Quicki index: 1/.log (fasting insulin $\mathrm{U} / \mathrm{ml}$ ) $+\log$ (fasting glucose, $\mathrm{mg} / \mathrm{dl})$;

iii. MATSUDA index: $10000 / \sqrt{ }($ fasting glucose $(\mathrm{mg} / \mathrm{dl}) \mathrm{x}$ basal insulin $(\mathrm{uU} / \mathrm{ml}))$ x (mean OGTT glucose x mean insulin OGTT);

iv. 1/Insulin: 1/Basal Insulin

v. Oral Glucose Insulin sensitivity (OGIS) available at http://www. isib.cnr.it/ogis/;

Finally we calculated the indices that together evaluate the function of the beta cell thanks to the product of an index of secretion by index of action of insulin

\section{Beta cell function indexes}

Oral disposition index (ODI): EII x 1/basal insulin;

\section{IS/IR index: EII x MATSUDA;}

We considered as confounding variables in the analysis: age in years, gender expressed as men and women, BMI calculated based on the formula weight $(\mathrm{kg}) /$ height $\left(\mathrm{m}^{2}\right)$ classified subjects according to the WHO 2013 underweight: <19; Normal Weight: 19-24.9; Overweight: 25-29.9; Obesity $>30$.

For statistical analysis, the Kolmogorov-Smirnov test was used to assess the distribution of (normal or abnormal) variables: all quantitative continuous variables had non-normal distribution, so the descriptive statistic used was median and interquartile range to determine the clinical and demographic characteristics of patients. While in the qualitative or nominal variables, frequency and percentage were used.

To determine differences in beta cells secretion and insulin action indexes between medians according to gender, status of glucose tolerance and weight categories the Mann-Whitney and KruskalWallis test were used. For the analysis of correlation and concordance between indexes, negative values of Early insulinogenic index were excluded. 
In the multivariate analysis: we calculated Spearman correlation coefficient between the components of the known and the new proposed oral disposition indexes. Finally we calculated the correlation between ODI and our index. We determined value of concordance (kappa) between oral disposition indexes with the values of the $75^{\text {th }}$ percentile of each one. To analyze these data, the SPSS version 20 was used.

\section{Results}

Of the 2097 patients just 1619 patients met selection criteria. The median age of the population was 43years (31-53), median weight was $83 \mathrm{~kg}$ (64-96), median BMI of 32 (26-36), median values of SBP and DBP were normal 118 and $77 \mathrm{mmHg}$, respectively.

The basal blood glucose level was 92 (83-99)mg/dl and 122(95139)mg/dl after 2hours. Fasting insulin was $13(6-15) \mu \mathrm{U} / \mathrm{ml}$ and 85 $(37-102) \mu \mathrm{U} / \mathrm{ml}$ at $120 \mathrm{~min}$. The median value of triglycerides was $133(101-164) \mathrm{mg} / \mathrm{dl}$, median cholesterol value was 183 (159-206) $\mathrm{mg} / \mathrm{dl}$, HDL 43(35-49)mg/dl, LDL 114(92-133)mg/dl and non-HDL cholesterol 140(117-160)mg/dl (Table 1). 73\%(1177) were women and 27\%(442)men, their general characteristics are presented in Table 2. The median weight value was significantly higher in men $96 \mathrm{~kg}$ $(p<0.00)$, but no significant differences in BMI were found. The values of SBP and DBP also showed significant differences between genders with higher values in men with SBP $123 \mathrm{mmHg}$ and DBP $79 \mathrm{mmHg}$ (p 0.00). Baseline values of glucose and insulin were higher in men with glucose $93 \mathrm{mg} / \mathrm{dl}$ and insulin $15 \mathrm{IU} / \mathrm{L}$ (p 0.00), while the values of both glucose and insulin at 2 hours afterload were not significantly different.

Table I Overview of the study population

\begin{tabular}{|c|c|c|c|}
\hline & Variables & Median & $\begin{array}{l}\text { Interquartile } \\
\text { range }\end{array}$ \\
\hline \multirow[t]{9}{*}{$n=1619$} & Age(Years) & 39 & $29-50$ \\
\hline & Weight(kg) & 75 & $64-94$ \\
\hline & $\operatorname{BMI}\left(\mathrm{kg} / \mathrm{m}^{2}\right)$ & 29.5 & $26-36$ \\
\hline & $\mathrm{SP}(\mathrm{mmHg})$ & 120 & $110-120$ \\
\hline & $\mathrm{DP}(\mathrm{mmHg})$ & 80 & $70-80$ \\
\hline & Basal Insulin $(\mu \mathrm{Ul} / \mathrm{ml})$ & 8,8 & |4-Jun \\
\hline & Insulin $2 \mathrm{hs}(\mu \mathrm{UI} / \mathrm{ml})$ & 52 & $32-84$ \\
\hline & Basal glucose(mg/dl) & 87 & $81-92$ \\
\hline & Glucose $2 \mathrm{hs}(\mathrm{mg} / \mathrm{dl})$ & 105 & $88-119$ \\
\hline \multirow[t]{5}{*}{$n=1099$} & $\mathrm{TG}(\mathrm{mg} / \mathrm{dl})$ & 124 & $95-160$ \\
\hline & $\mathrm{CHOL}(\mathrm{mg} / \mathrm{dl})$ & 178 & $155-204$ \\
\hline & $\mathrm{HDL}(\mathrm{mg} / \mathrm{dl})$ & 42 & $35-50$ \\
\hline & $\mathrm{LDL}(\mathrm{mg} / \mathrm{d})$ & 108 & $90-|3|$ \\
\hline & No HDL(mg/dl) & 134 & $113-158$ \\
\hline
\end{tabular}

Table 2 Description of study population according to sex

\begin{tabular}{|c|c|c|c|c|c|c|}
\hline & Variables & Women & & \multicolumn{2}{|l|}{ Men } & $\mathbf{P}$ \\
\hline & $\% /$ Cases & $1177(73 \%)$ & & $442(2$ & & \\
\hline \multirow[t]{8}{*}{$n=1619$} & Age & 43 & $32-53$ & 42 & $30-52$ & 0,99 \\
\hline & Weight & 73,5 & $63-90$ & 88 & $72-111$ & 0,00 \\
\hline & $\mathrm{BMI}$ & 30 & $26-36$ & 31 & $26-37$ & 0,31 \\
\hline & $\begin{array}{l}\text { Basal } \\
\text { Insulin }\end{array}$ & 9,6 & $6,3-15$ & 9,4 & 18-Jun & 0,01 \\
\hline & Insulin $2 \mathrm{hs}$ & 63 & $37-101$ & 61 & $34-108$ & 0,26 \\
\hline & $\begin{array}{l}\text { Basal } \\
\text { Glucose }\end{array}$ & 91 & $83-99$ & 91 & $84-100$ & 0,00 \\
\hline & $\begin{array}{l}\text { Glucose } \\
2 \mathrm{hs}\end{array}$ & 116 & $97-139$ & 117 & $93-139$ & 0,51 \\
\hline & $\% /$ cases & $822(75 \%)$ & & $277(2$ & & \\
\hline \multirow[t]{5}{*}{$n=1099$} & TG & 128 & $99-163$ & 134 & $107-169$ & 0,00 \\
\hline & $\mathrm{CHOL}$ & 183 & $\begin{array}{l}161- \\
207\end{array}$ & 176 & $150-202$ & 0,52 \\
\hline & $\mathrm{HDL}$ & 43 & $36-51$ & 37 & $33-43$ & 0,00 \\
\hline & LDL & 111 & $93-133$ & 107 & $90-131$ & 0,20 \\
\hline & No HDL & 139 & $\begin{array}{l}117- \\
159\end{array}$ & 135 & $|14-16|$ & 0,04 \\
\hline
\end{tabular}

In the lipid profile, the values of total cholesterol and LDL cholesterol were not significantly different between genders. In men triglyceride levels were higher compared with women (p 0.00).

In women the values of HDL cholesterol were not higher relative to men ( $\mathrm{p} 0.00)$, whereas HDL cholesterol levels were significantly lower (p 0.00)

$816(50 \%)$ had a BMI $>30,500(31 \%)$ were considered overweight, $285(18 \%)$ and 18 normal-weight (1\%) were underweight. Their characteristics are shown in Table 3.

The group of subjects with low weight showed the lowest median age of 34 years $(24-37 ; \mathrm{p} 0.00)$. The group of overweight subjects showed the highest median age 45 (34-55; p 0.00), also the highest median cholesterol value of $187 \mathrm{mg} / \mathrm{dl}(161-208 ; \mathrm{p} 0.00)$, LDL cholesterol 116mg/dl (95-135; p 0.00), non-HDL cholesterol 143mg/ dl (119-163; p 0.00).

The group of obese subjects had the highest median SBP $121 \mathrm{mmHg}$ (110-130; p 0.00), DBP 79mmHg (70-85; p 0.00), fasting glucose $93 \mathrm{mg} / \mathrm{dl}$ (84- 100; p 0.00), two hours post-load glucose $126 \mathrm{mg} / \mathrm{dl}$ (101-143; p 0.00), basal insulin $16 \mu \mathrm{UI} / \mathrm{ml}(9-20$, p 0.00$)$, two hours post-load insulin $98 \mu \mathrm{UI} / \mathrm{ml}$ (45 to $121 ; \mathrm{p} 0.00$ ), triglycerides $136 \mathrm{mg} /$ $\mathrm{dl}(106-167 ; \mathrm{p} 0.00)$. They also had the lowest median value of HDL cholesterol 41mg/dl (34-48; p 0.00).

$1039(64 \%)$ were categorized as normal glucose tolerance, 175 (11\%) with IFG, 194 (12\%) with IGT, 139 (9\%) with IGT + IFG and finally 72 (4\%) with T2DM (Table 4). 
Table 3 Description of the study population according to BMI

\begin{tabular}{|c|c|c|c|c|c|c|c|c|c|c|}
\hline & Variables & \multicolumn{2}{|c|}{ Low weight } & \multicolumn{2}{|c|}{ Normal weight } & \multicolumn{2}{|c|}{ Over weight } & \multicolumn{2}{|c|}{ Obesity } & $\mathbf{p}$ \\
\hline \multirow[b]{2}{*}{$n=1619$} & Cases $1 \%$ & \multicolumn{2}{|c|}{$18(1 \%)$} & \multicolumn{2}{|c|}{$285(18 \%)$} & \multicolumn{2}{|c|}{$500(31 \%)$} & \multicolumn{2}{|c|}{$816(50 \%)$} & \\
\hline & Age & 27 & $24-37$ & 45 & $30-56$ & 45 & $34-55$ & 40 & $31-50$ & 0,00 \\
\hline & Basal Glucose & 86 & $79-87$ & 89 & $81-96$ & 90 & $84-99$ & 92 & $84-100$ & 0,00 \\
\hline & Glucose 2 hs & 102 & $79-129$ & III & $88-134$ & 115 & $95-137$ & 119 & $101-143$ & 0,00 \\
\hline & Basal insulin & 5 & 7-Feb & 6 & 9-Apr & 8 & 12-Jun & 13 & 20-Sep & 0,00 \\
\hline & Insulin 2 hs & 60 & $37-99$ & 42 & $26-62$ & 60 & $36-91$ & 76 & $45-12 \mid$ & 0,00 \\
\hline & Cases/ \% & 13( & & 186 & & 338 & |\%) & 562( & & 0,00 \\
\hline \multirow[t]{5}{*}{$n=1099$} & Triglycerides & 192 & $73-151$ & 118 & $82-156$ & $|3|$ & $103-164$ & 133 & $106-167$ & 0,00 \\
\hline & Cholesterol & 161 & $156-175$ & 184 & I58-208 & 186 & $|6|-208$ & 177 & I57-203 & 0,00 \\
\hline & $\mathrm{HDL}$ & 49 & $47-59$ & 43 & $37-53$ & 43 & $37-50$ & 40 & $34-48$ & 0,00 \\
\hline & LDL & 86 & $81-97$ & 110 & $92-132$ & 113 & $94-135$ & 111 & $91-132$ & 0,00 \\
\hline & No HDL & 113 & $100-117$ & 136 & $112-158$ & $|4|$ & $119-163$ & 138 & $117-159$ & 0,00 \\
\hline
\end{tabular}

Table 4 Description of population by status of glucose tolerance

\begin{tabular}{|c|c|c|c|c|c|c|c|}
\hline & Variables & IFG & IGT & IFG+IGT & DM & Normal & $\mathbf{p}$ \\
\hline & \# CASES/\% & $175(\mid 1 \%)$ & $194(12 \%)$ & I39(9\%) & $72(4 \%)$ & $1039(64 \%)$ & \\
\hline \multirow[t]{11}{*}{$N=1619$} & Age & 45 & 45 & 50 & 49 & 39 & 0,00 \\
\hline & & $38-55$ & $35-53$ & $4 \mid-58$ & $36-57$ & $29-49$ & \\
\hline & Weight & 75 & 78 & 85 & 79 & 75 & 0,00 \\
\hline & & $68-98$ & $67-92$ & $70-102$ & $60-100$ & 63.93 & \\
\hline & BMI & 30 & 31 & 33 & 31 & 30 & 0,00 \\
\hline & & $27-36$ & $27-36$ & $28-41$ & $28-37$ & $25-35$ & \\
\hline & Basal Insulin & II & II & 13 & 13 & 9 & 0,00 \\
\hline & & I8-Aug & 16-Aug & $2 \mathrm{I}-\mathrm{Sep}$ & 2I-Aug & I4-Jun & \\
\hline & Insulin 2 hs & 62 & 100 & 95 & 96 & 52 & 0,00 \\
\hline & & $42-153$ & $71-179$ & $70-160$ & $50-|4|$ & $31-84$ & \\
\hline & & $123(1 \mid \%)$ & 132 (I2\%) & $94(9 \%)$ & 44 (4\%) & 706 (64\%) & \\
\hline \multirow[t]{10}{*}{$N=1099$} & Triglycerides & 132 & 149 & 148 & 144 & 124 & 0,00 \\
\hline & & $107-162$ & $115-176$ & $108-172$ & $115-175$ & $95-160$ & \\
\hline & Cholesterol & 184 & 191 & 185 & 188 & 178 & 0,00 \\
\hline & & $164-210$ & $162-210$ & $|6|-203$ & $158-212$ & I55-204 & \\
\hline & $\mathrm{HDL}$ & 41 & 42 & 40 & 35 & 42 & 0,00 \\
\hline & & $36-49$ & $36-50$ & $35-46$ & $31-44$ & $35-50$ & \\
\hline & LDL & 116 & 114 & 113 & 124 & 108 & 0,02 \\
\hline & & $101-135$ & $96-140$ & $95-130$ & $89-139$ & $90-131$ & \\
\hline & No HDL & 142 & 144 & $14 \mid$ & 153 & 134 & 0,00 \\
\hline & & $125-167$ & $121-167$ & $126-162$ & $121-173$ & $113-158$ & \\
\hline
\end{tabular}

Subjects with normal glucose tolerance had the lowest median value of age (40years) $(\mathrm{p}<0.00)$, lower BMI $(31)(\mathrm{p}=<0.00)$ relative to other status, in addition to lower median values triglycerides, LDL cholesterol and non-HDL (p 0.00).

The status of IFG cases in this group had total cholesterol and higher LDL cholesterol. On the status of IGT presented the highest afterload insulin value at 2 hours and the highest triglyceride value.
The status of IFG + IGT had highest median value of age in the population and values higher SBP and DBP was evident with respect to the other status is presented.

In the group whose values in the OGTT were consistent with DM2 the highest median value of basal insulin and glucose afterload were present. They also had the lowest HDL cholesterol value. Calculating insulin secretion indexes was performed and showed significant differences by sex, BMI and status of glucose tolerance (Table 5). 
Table $\mathbf{5}$ Indexes of insulin secretion in the study population by sex, BMI and status of glucose tolerance

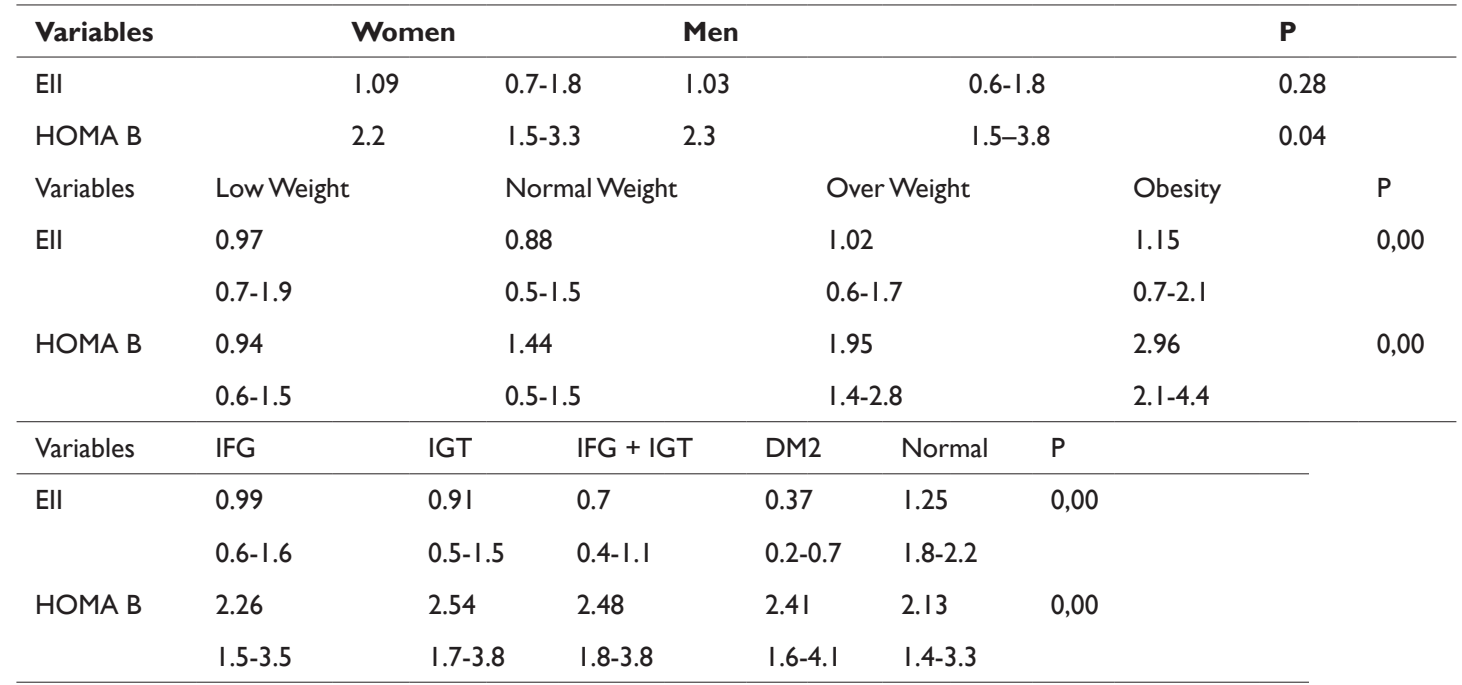

Indexes of insulin action (HOMA IR, QUICKI, 1/INSULIN, BMI and glucose tolerance status (Table 6).

MATSUDA, OGIS) was calculated and its value was stratified by sex,

Table 6 Indices of insulin action in the study population by BMI and status of glucose tolerance

\begin{tabular}{|c|c|c|c|c|c|c|c|c|c|}
\hline \multicolumn{2}{|l|}{ Variables } & \multicolumn{2}{|c|}{ Low weight } & \multicolumn{2}{|c|}{ Normal weight } & Over weight & \multicolumn{2}{|l|}{ Obesity } & $\mathbf{P}$ \\
\hline Cases/ \% & & $18(1 \%)$ & & $285(18 \%)$ & & $500(31 \%)$ & $816(50 \%)$ & & \\
\hline HOMA IR & & 0.78 & & 1.35 & & 1.91 & 3.05 & & \\
\hline Quicki & & 0.4 & & 0.37 & & 0.35 & 0.32 & & \\
\hline I/Insulin & & 0.3 & & 0.2 & & 0.12 & 0.07 & & \\
\hline Matsuda & & 7 & & 6 & & 4 & 3 & & \\
\hline OGIS2 & & 456 & & 442 & & 404 & 369 & & \\
\hline Vablesria & IFG & & IGT & & $\mathrm{IFG}+\mathrm{IGT}$ & $\mathrm{DM} 2$ & & Normal & $P$ \\
\hline Cases/ \% & I75(II\%) & & 194(12\%) & & 139 (9\%) & 72 (4\%) & & $1039(64 \%)$ & \\
\hline HOMA IR & 2.99 & & 2.34 & & 3.5 & 4 & & 1.95 & 0,00 \\
\hline Quicki & 0.32 & & 0.34 & & 0.32 & 0.31 & & 0.35 & 0,00 \\
\hline I/Insulin & 0.09 & & 0.09 & & 0.08 & 0.07 & & 0.11 & 0,00 \\
\hline Matsuda & 2.8 & & 2.98 & & 2.3 & 2.3 & & 4.6 & 0,00 \\
\hline OGIS2 & 352 & & 375 & & 323 & 324 & & 425 & 0,00 \\
\hline
\end{tabular}

For analysis of correlation and concordance between indexes, EII negative values were excluded. Within the study population, 30 subjects had a negative early insulinogenic index, their general characteristics at Table 7 .

Table 7 Description of the population with early insulinogenic index with negative values

\begin{tabular}{llll}
\hline & Women & Men & P \\
\hline Cases/\% & $19(63 \%)$ & II (37\%) & \\
Age(Years) & $39(30-44)$ & 3 I $(19-46)$ & 0,103 \\
Weight & $78(59-104)$ & $88(69-107)$ & 0,158 \\
BMI & $32(26-35)$ & 3 I (25-35) & 0,966 \\
Basal Glucose & $92(82-98)$ & $98(87-104)$ & 0,307 \\
Glucose 30min & $93(73-95)$ & II3(74-I32) & 0,307 \\
Fasting Insulin & I2(5-I4) & $36(6-42)$ & 0,200 \\
Insulin 30min & 5 I (29-72) & $66(33-83)$ & 0,47 I \\
\hline
\end{tabular}

EII negative cases were also classified according to BMI and glucose tolerance status (Table 8).

Table 8 Categorization Ell negative patients by sex, BMI, and glucose tolerance status

\begin{tabular}{llll}
\hline Variables & Clasification & Women & Men \\
\hline Weight Categories & Low Weight & 0 & I \\
& Normal Weight & 2 & I \\
& OverWeight & 9 & 4 \\
& Obesity & 8 & 5 \\
Status of glucose & IFG & 1 & I \\
tolerance & IGT & 0 & 1 \\
& IFG+IGT & 0 & 0 \\
& DM2 & 3 & 2 \\
& NORMAL & 15 & 7
\end{tabular}


Of the 30 subjects with negative EII, 15 subjects had the glucose delta $0-30 \mathrm{~min}$ negative thus indicating that glucose values in OGTT return earliest form even lower than the baseline status and tolerance glucose was normal.

While 4 subjects showed delta insulin 0-30 negative, which mean low beta cell response to glucose stimulation, 3 subjects had DM2 status and only one had normal tolerance (female, 4lyears with BMI 27.7). The correlation between the oral disposition indexes and the possible new indices proposed (Table 9) Figure 1.

Table 9 Correlation between known disposition indexes (ODI - IR/IS) and proposed new indexes

\begin{tabular}{lllll}
\hline Variables & ODI & $\mathbf{P}$ & $\mathbf{I R / I S}$ & $\mathbf{P}$ \\
\hline HOMA B x I/Insulin & 0,422 & 0,00 & 0,519 & 0,00 \\
HOMA B x Matsuda & 0,213 & 0,00 & 0,470 & 0,00 \\
Ell x OGIS 2 & 0,773 & 0,00 & 0,808 & 0,00 \\
\hline
\end{tabular}
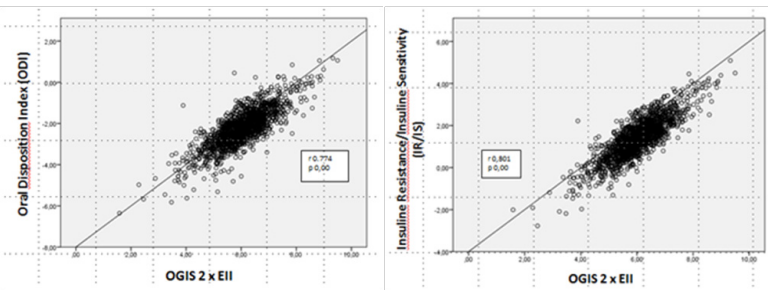

Figure I Correlation between known disposition indexes (ODI-IR/IS) and EII $\times$ OGIS 2.

The correlation between disposition indexes was stratified by BMI and status of glucose tolerance (Tables10\&11), (Figures 2\&3).

Table 10 Disposition indexes in the study population according to BMI

\begin{tabular}{|c|c|c|c|c|c|}
\hline Variables & $\begin{array}{l}\text { Low } \\
\text { weight }\end{array}$ & $\begin{array}{l}\text { Normal } \\
\text { weight }\end{array}$ & $\begin{array}{l}\text { Over } \\
\text { weight }\end{array}$ & Obesity & $\mathbf{P}$ \\
\hline Cases/ \% & $17(1 \%)$ & $282(18 \%)$ & 488 (31\%) & 804 (5I\%) & \\
\hline \multirow[t]{2}{*}{ ODI } & 0,33 & 0,14 & 0,12 & 0,09 & 0,00 \\
\hline & $0,21-0,59$ & $0,08-0,27$ & $0,06-0,2$ & $0,05-0,15$ & \\
\hline \multirow[t]{2}{*}{ IS/IR } & 10.2 & 5.7 & 4.2 & 3.5 & 0,00 \\
\hline & $7,13-13,5$ & 2,99-9,7 & $2,2-7,2$ & $1,96-6,19$ & \\
\hline \multirow[t]{2}{*}{$\begin{array}{l}\text { HOMA B x } \\
\text { I/Insulin }\end{array}$} & 0,24 & 0,23 & 0,23 & 0,23 & 0,00 \\
\hline & $0,24-0,27$ & $0,23-0,24$ & $0,22-0,23$ & $0,22-0,23$ & \\
\hline \multirow[t]{2}{*}{$\begin{array}{l}\text { HOMA B x } \\
\text { Matsuda }\end{array}$} & 7.18 & 8.9 & 8,1 & 8.5 & 0,00 \\
\hline & $6,3-10,2$ & $9-9,8$ & $8,3-8,9$ & $8,8-9,3$ & \\
\hline \multirow[t]{2}{*}{$\begin{array}{l}\text { HOMA B } x \\
\text { OGIS2 }\end{array}$} & 503 & 627 & 764 & 1076 & 0,00 \\
\hline & $3|4-68|$ & 457--892 & $550-1082$ & $774-1508$ & \\
\hline \multirow[t]{2}{*}{$\begin{array}{l}\text { Ell } x \\
\text { OGIS2 }\end{array}$} & 502 & 393 & 379 & 433 & 0,04 \\
\hline & $357-810$ & $233-676$ & $230-704$ & $258-728$ & \\
\hline
\end{tabular}

Table II Disposition indexes in the study population according to status of glucose tolerance

\begin{tabular}{|c|c|c|c|c|c|c|}
\hline Variables & IFG & IGT & IFG+IGT & DM2 & Normal & $\mathbf{P}$ \\
\hline Cases/\% & I73(II\%) & $193(12 \%)$ & $139(9 \%)$ & $67(4 \%)$ & $1019(64 \%)$ & \\
\hline ODI & $\begin{array}{l}0,08 \\
0,09-0,13\end{array}$ & $\begin{array}{l}0,076 \\
0,05-0,11\end{array}$ & $\begin{array}{l}0,05 \\
0,03-0,08\end{array}$ & $\begin{array}{l}0,03 \\
0,006-0,098\end{array}$ & $\begin{array}{l}0,14 \\
0,09-0,23\end{array}$ & 0,00 \\
\hline IS/IR & $\begin{array}{l}2.8 \\
1,8-4,2\end{array}$ & $\begin{array}{l}2.6 \\
1,7-3,7\end{array}$ & $\begin{array}{l}1,6 \\
0,99-2,14\end{array}$ & $\begin{array}{l}0.83 \\
0,25-2,59\end{array}$ & $\begin{array}{l}5.7 \\
3,6-9,5\end{array}$ & 0,00 \\
\hline $\begin{array}{l}\text { HOMA B } \\
\text { I/insulin }\end{array}$ & $\begin{array}{l}0,19 \\
0,19-0,20\end{array}$ & $\begin{array}{l}0,22 \\
0,22-0,23\end{array}$ & $\begin{array}{l}0,19 \\
0,18-0,19\end{array}$ & $\begin{array}{l}0,185 \\
0,17-0,19\end{array}$ & $\begin{array}{l}0,24 \\
0,24 I-0,245\end{array}$ & 5,00 \\
\hline $\begin{array}{l}\text { HOMA B } \\
\text { Matsuda }\end{array}$ & $\begin{array}{l}6,9 \\
6,8-7,1\end{array}$ & $\begin{array}{l}7,5 \\
7,4-8,0\end{array}$ & $\begin{array}{l}5,7 \\
5,7-6,1\end{array}$ & $\begin{array}{l}5,5 \\
5,2-6\end{array}$ & $\begin{array}{l}9.8 \\
10-10,4\end{array}$ & 0,00 \\
\hline $\begin{array}{l}\text { HOMA B } x \\
\text { OGIS } 2\end{array}$ & $\begin{array}{l}766 \\
533-1107\end{array}$ & $\begin{array}{l}942 \\
662-1374\end{array}$ & $\begin{array}{l}780 \\
596-1106\end{array}$ & $\begin{array}{l}760 \\
526-1073\end{array}$ & $\begin{array}{l}910 \\
621-1303\end{array}$ & 0,00 \\
\hline $\begin{array}{l}\text { Ell } \times \text { OGIS } \\
2\end{array}$ & $\begin{array}{l}326 \\
212-544\end{array}$ & $\begin{array}{l}320 \\
210-456\end{array}$ & $\begin{array}{l}223 \\
|43-33|\end{array}$ & $\begin{array}{l}122 \\
36-458\end{array}$ & $\begin{array}{l}537 \\
343-869\end{array}$ & 0,00 \\
\hline
\end{tabular}

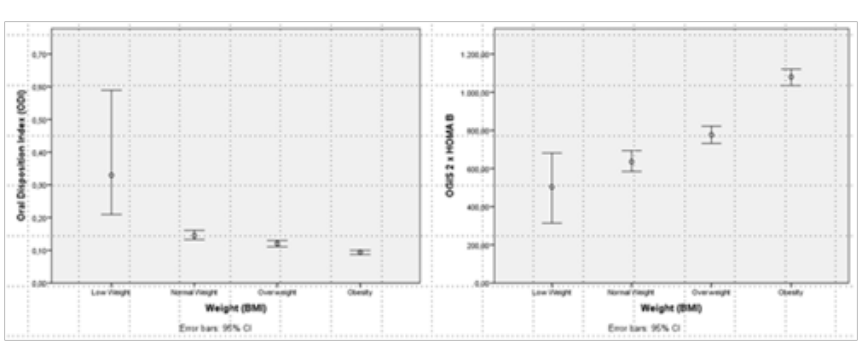

Figure 2 Disposition indexes in the study population according to BMI.

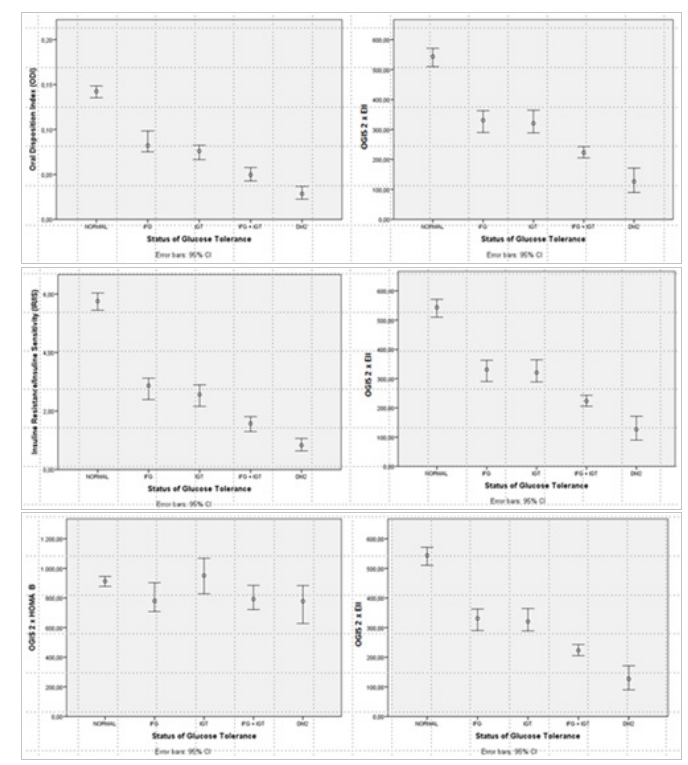

Figure 3 Disposition indexes in the study population according to status of glucose tolerance.

Finally the concordance between the known oral indexes and the proposed new index with better correlation (EII x OGIS) by calculating kappa was evaluated. 
Table 12 Concordance between disposition indexes

\begin{tabular}{|c|c|c|c|c|c|c|c|c|c|}
\hline Variables & & ODI & & & & IR/IS & & & \\
\hline \multirow{3}{*}{ Ell $\times$ OGIS 2} & & $\mathrm{P}<75$ & $p>75$ & kappa & $\mathrm{P}$ & $\mathrm{p}<75$ & $p>75$ & kappa & $\mathrm{P}$ \\
\hline & $\mathrm{p}<75$ & 1053 & 146 & 0,518 & 0,025 & 1055 & 139 & 0,536 & 0,025 \\
\hline & $p>75$ & 140 & 252 & & & 138 & 259 & & \\
\hline
\end{tabular}

\section{Discussion}

In this study two new disposition indexes (OGIS x HOMA B and OGIS x EII) were evaluated and compared with the two available and known oral disposition indexes. Analyzing the OGTT and insulin curves 3 to 5hours was performed. 1619 curves were included in the final analysis.

There were a higher percentage of women $(73 \%)$ in our study population. Men showed significantly greater weight ( $\mathrm{p} 0.00)$, basal insulin values ( $p 0.01$ ), glucose ( $p$ 0.00) and triglycerides ( $p 0.00)$ than women. Women as we expect showed significantly higher HDL cholesterol than men ( $\mathrm{p} 0.00$ ). The population was divided by weight class and found that only $18 \%$ had normal weight $(\mathrm{BMI}<25)$. The majority of subjects were overweight or obese $(31 \%$ overweight and $50 \%$ obese)

This finding was expecting in hospital population like us with high risk to development type 2diabetes. The secretion insulin index, early insulinogenic index (EII), was similar between men and women. As we expected the highest value was associated with low weight in both genders.

We also find that value of EII fell in the presence of any abnormality in glucose tolerance (normal 1.6, IFG 1.2, IGT 1.1 and DM2 1.0; p 0.00 ). In contrast the value of HOMA B index was significantly higher in men ( 3.2 vs $2.8 ; \mathrm{p} 0.036$ ). Surprisingly, the highest values were found in the obese population (3.6vs1.7 in normal weight; $\mathrm{p} 0.00$ ).

This result may be associated with increased insulin resistance in this population (basal insulin $16 \mathrm{mUI} / \mathrm{ml}$ vs $7 \mathrm{mUI} / \mathrm{ml}$ normal weight; $\mathrm{p}$ 0.00). Finally higher HOMA B was found in DM2 and IGT (3.3), this result may reflect the increase in fasting glucose and insulin.

In relation to insulin action indexes, our work shows results similar to those described in previous studies, where the HOMA IR values are higher in subjects with BMI $>30$ as well as lower values for Quicki, MATSUDA, OGIS2 and OGIS3 indexes. Our study showed that HOMA IR was higher in subjects with IFG+IGT and lowest in subjects with normal glucose tolerance (cannot assess HOMA IR in subjects with DM2).

The Quicki, 1/insulin, Matsuda and OGIS indexes showed a similar pattern with respect to glucose tolerance, with higher values in people with normal tolerance and lower in patients with T2DM. The only exceptions were OGIS and Matsuda with values in IFG+IGT cases lower than T2DM.

We recall that only $4 \%$ of the population was diabetic, this result may reflect the lack of $\mathrm{n}$ in this group. 30 subjects with EII negative were excluded, of which $19(63 \%)$ were female and 11 (37\%) were men, but no significant differences were found between them in terms of their general characteristics. These results may be associated with the value of $\mathrm{n}$ in this group.

We divided this subset by weight class and a similar number of overweight subjects..$^{13-15}$ and obesity (13) was found. In addition, these subjects were divi Figure 1 Correlation between known disposition indexes (ODI-IR/IS) and EII x OGIS 2. ded by glucose tolerance: 12 subjects with normal tolerance, 3 prediabetics and 5 diabetic subjects were found.

This result agrees to the publication of Abdul-Ghani et al. ${ }^{16}$ They suggest that subjects with EII negative and normal glucose tolerance have higher insulin sensitivity which explains why during OGTT glucose values return quickly under baseline. They propose that these patients are at low risk of progression to type 2 diabetes. ${ }^{17-22}$

Furthermore Mirjam V et al. ${ }^{23}$ infer that subjects EII negative with insulin delta 0-30 negative indicating a low reserve of the beta cell and increased susceptibility to DM2. ${ }^{24-28}$ BMI was considered the most important confounding factor. The best correlation was found between IR/IS and EII x OGIS 2; r 0.809 (p 0.00). The highest correlation value obtained according to the status of tolerance was in the DM2 group IR/IS and EII x OGIS2 (r 0.997; p 0.00). The concordance between the known oral disposition index IR/IS and OGIS2 x EII was 0.557 (p 0.00).

\section{Limitations}

The observational design did not allow tracking of subjects to establish the causal relationship between the different status of glucose tolerance and values of the proposed index.

The study group does not represent the general population, but allowed to identify the prevalence of different glucose tolerance status and describe their clinical characteristics.

The selection of patients represented the largest bias in our study, because at our institute, OGTT is applicate to subjects with high risk: dyslipidemia, obesity, hypothyroidism, chronic steroid use, menstrual abnormalities, hyperandrogenism or reactive hypoglycemia.

\section{Conclusion}

Our study showed that a new oral disposition index with EII as an insulin secretion index and OGIS as insulin action one has good correlation and concordance with known disposition indexes.

It is necessary to validate this index at prospective studies that allow us to evaluate their ability to discriminate individuals at high risk of progression to T2DM and compare it with values obtained in the clamp studies.

\section{Acknowledgments}

None.

\section{Conflicts of interest}

The authors declare that there are no conflicts of interest.

\section{Funding}

None. 


\section{References}

1. Chen T, Xu F, Su JB, et al. Glycemic variability in relation to oral disposition index in the subjects with different stages of glucose tolerance. Diabetol Metab Syndr. 2013;5:38.

2. Schiavon M, Hinshaw L, Mallad A, et al. Assessment of-cell function in humans, simultaneously with insulin sensitivity and hepatic extraction, from intravenous and oral glucose tests. Am J Physiol Endocrinol Metab. 2007;293(4):E1-E15.

3. De Fronzo R, Tobin J, Andres R. Glucose clamp technique: a method for quantifying insulin secretion and resistance. Am J Physiol. 1979;237(3):E214-E223.

4. Lorenzo C, Wagenknecht LE, Rewers MJ, et al. Disposition Index, Glucose Effectiveness and Conversion to Type 2 Diabetes. Diabetes Care. 2009;33(9):2098-2103.

5. Muniyappa R, Lee S, Chen H, et al. Current approaches for assessing insulin sensitivity and resistance in vivo: advantages, limitations, and appropriate usage. Am J Physiol Endocrinol Metab. 2008;294(1):E15E26.

6. Soonthornpun S, Setasuban W, Thamprasit A, et al. (2003) Novel Insulin Sensitivity Index Derived from Oral Glucose Tolerance test. J Clin Endocrinol Metab. 2003;88(3):1019-1023.

7. Mari A, Pacini G, Brazzale AR, et al. Comparative evaluation of simple insulin sensitivity methods based on the oral glucose tolerance test. Diabetologia. 2005;48(4):748-751.

8. Sjaarda LG, Bacha F, Lee S, et al. Oral Disposition Index in Obese Youth from Normal to Prediabetes to Diabetes: Relationship to Clamp Disposition Index. J Pediatr. 2012;161(1):51-57.

9. Utzschneider KM, Prigeon RL, Faulenbach MV, et al. Oral Disposition Index Predicts the Development of Future Diabetes Above and Beyond Fasting and 2-h Glucose Levels. Diabetes Care. 2009;32(2):335-341.

10. Pisprasert V, Ingram KH, Lopez-Davila MF, et al. Limitations in the use of indices using glucose and insulin levels to predict insulin sensitivity. Diabetes Care. 2013;36(4):845-853.

11. Matsuda M, DeFronzo RA. Insulin Sensitivity Indices Obtained From Oral Glucose Tolerance Testing. Diabetes Care. 1999;22(9):1462-1470.

12. Mari A, Pacini G, Murphy E, et al. A Model-Based Method for Assessing Insulin Sensitivity From the Oral Glucose Tolerance Test. Diabetes Care. 2001;24(3):539-548.

13. Retnakaran R, Qi Y, Goran MI, et al. Evaluation of proposed oral disposition index measures in relation to the actual disposition index, Diabet Med. 2009;26(12):1198-1203.

14. Antonio BC, Arturo RG, Mario AMA. Escenario actual de la obesidad en México. Rev Med Inst Mex Seguro Soc. 2013;51(3):292-299.
15. Staten MA, Kelley DE. Using Oral Challenge Testing to Assess Insulin Action and Secretion With Mathematical Modeling. Diabetes. 2014;63(4):1188-1190.

16. Abdul-Ghani MA, Williams K, DeFronzo RA, et al. What Is the Best Predictor of Future Type 2 Diabetes? Diabetes Care. 2007;30(6):1544-1548.

17. DeFronzo RA, Abdul-Ghani MA. Oral disposition index predicts the development of future diabetes above and beyond fasting and $2-\mathrm{h}$ glucose levels: response to Utzschneider et al. Diabetes Care. 2009;32(7):e86.

18. Abdul-Ghani MA, Williams K, DeFronzo R, et al. Risk of Progression to Type 2 Diabetes Based on Relationship Between Post load Plasma Glucose and Fasting Plasma Glucose. Diabetes Care. 2006;29(7):1613-1618.

19. Bhatnagar MK, Arora S, Singh V, et al. Assessment of insulin resistance using surrogate markers in patients of metabolic syndrome. Diabetes Metab Syndr. 2011;5(1):29-32.

20. Oka R, Yagi K, Sakurai M, et al. Insulin secretion and insulin sensitivity on the oral glucose tolerance test (OGTT) in middle-aged Japanese. Endocr J. 2012;59(1):55-64.

21. Aizawa T, Yamada M, Katakura M, et al. Hyperbolic correlation between insulin sensitivity and insulin secretion fades away in lean subjects with superb glucose regulation; Endocr J. 2012;59(2):127-136.

22. Chen T, Xu F, Su JB, et al. Glycemic variability in relation to oral disposition index in the subjects with different stages of glucose tolerance. Diabetol Metab Syndr. 2013;5:38.

23. Faulenbach MV, Wright LA, Lorenzo C, et al. Impact of Differences in Glucose Tolerance on the Prevalence of a Negative Insulinogenic Index. J Diabetes Complications. 2013;27(2):158-161.

24. García-Fuentes. Homeostatic Model Assessment (HOMA). Aplicaciones prácticas. Av Diabetol. 2008;24(4):291-295.

25. Chen G, Liu C, Yao J, et al. Overweight, obesity, and their associations with insulin resistance and $\beta$-cell function among Chinese: a crosssectional study in China. Metabolism Clinical and Experimental. 2010;59(12):1823-1832.

26. Chen G, Liu C, Chen F, et al. Body fat distribution and their associations with cardiovascular risk, insulin resistance and b-cell function: are there differences between men and women? Int J Clin Pract. 2011;65(5):592-601.

27. Hisako K, Kazuhiko S, Kazuo T, et al. Age-dependent decline in b-cell function assessed by an oral glucose tolerance test-based disposition index. Journal of Diabetes Investigation. 2011;2(4):1-4.

28. Bergman RN, Stefanovski D, Kim SP. Systems analysis and the prediction and prevention of Type 2 diabetes mellitus. Curr Opin Biotechnol. 2014;28:165-170. 